NBER WORKING PAPER SERIES

MEAN REVERSION AND CONSUMPTION SMOOTHING

Fischer Black

Working Paper No. 2946

NATIONAL BUREAU OF ECONOMIC RESEARCH 1050 Massachusetts Avenue

Cambridge, MA 02138

April 1989

I am grateful to William Brock, George Constantinides, James Poterba, Robert Stambaugh, and especially to Robert Merton for comments on a previous draft. This paper is part of NBER's research program in Financial Markets and Monetary Economics. Any opinions expressed are those of the author not those of the National Bureau of Economic Research. 


\section{MEAN REVERSION AND CONSUMPTION SMOOTHING}

\section{ABSTRACT}

Using a simple conventional model with additive separable utility and constant elasticity, we can explain mean reversion and consumption smoothing. The model uses the price of risk and wealth as state variables, but has only one stochastic variable. The price of risk rises temporarily as wealth falls. We also distinguish between risk aversion and the consumption elasticity of marginal utility. We can use the model to match estimates of the average values of consumption volatility, wealth volatility, mean reversion, the growth rate of consumption, the real interest rate, and the market risk premium.

Fischer Black

Goldman, Sachs \& Co.

85 Broad Street, 29th Floor

New York, NY 10004 


\title{
MEAN REVERSION AND CONSUMPTION SMOOTHING
}

\author{
Fischer Black*
}

\section{INTRODUCTION}

Fama and French (1988), Poterba and Summers (1988) and others seem to find mean reversion in common stock prices. Over intervals of several years, they find that a decline in prices has been associated with a rise in expected return, and a rise in prices has been associated with a decline in expected return.

Expected returns are not observable, so it's hard to estimate the process by which expected returns change, as Merton (1980) and Summers (1986) point out.

Moreover, the amount of mean reversion in the market may change over time. Black (1988) suggests that changing mean reversion may help us understand the stock market crash of 1987. In the postwar period, Kim, Nelson, and Startz (1988) point out that the Fama and French estimates of mean reversion do not differ significantly. from zero. On average, though, there may well be some mean reversion in stock prices and expected returns. Mean reversion can occur in two ways: first, the expected return on the market can go in a direction opposite to that of the market; and second, the expected return can revert toward a mean level. Cecchetti, Lam, and Mark (1988) show that the amount of mean reversion we have seen is consistent with equilibrium asset pricing. They also discuss the tie between mean reversion and consumption smoothing.

-I am grateful to William Brock, George Constantinides, James Poterba, Robert Stambaugh. and especially to Robert Merton for comments on a previous draft. 
Hall $(1978,1988)$, Hansen and Singleton (1983) and others find consumption surprisingly smooth relative to income and asset prices. This may be due in part to liquidity constraints, as discussed by Zeldes (1988), in part to "rule-of-thumb" consumption, as discussed by Campbell and Mankiw (1989), and in part to habit formation, as discussed by Sundaresan (1985) and Constantinides (1988). As I hope to show in this paper, it may also be due to a process that gives mean reversion in asset prices and expected returns. The mean reversion in asset returns may also be related to the mean reversion in GNP observed by Cochrane (1988).

Mehra and Prescott (1985) find that they are unable to reconcile such facts as smooth consumption, a high risk premium in the stock market and a low real interest rate in a model with additive separable utility. The model $I$ use is in the spirit of theirs: what I add is a new definition of risk aversion. Prescott (1986) gives an overview of the relation between this kind of model and the stylized facts about business cycles.

I believe that we can explain all of these stylized facts in a conventional model without such features as liquidity constraints and habit formation. The model in this paper is a special case of the Merton (1973) models of uncertainty in technology, as expanded by Brock (1982). It is close to Merton's more specific models $(1969,1971)$, but has an uncertain price of risk.

We use an additive separable utility function with constant relative risk aversion and a constant utility discount rate. Whenever the derived utility function has more than one state variable, the notion of "risk aversion" becomes ambiguous. What's conventionally called "risk aversion" we split into two concepts: an "elasticity" that fixes the volatility of consumption, and a "risk aversion" that fixes the amount of market risk the typical investor wants to take for a given price of risk. With two state variables, elasticity and risk aversion can differ, and risk aversion can vary even when elasticity is constant. I feel that my definition of risk aversion matches the parameter that researchers like Friend and Blume (1975) have estimated. Epstein (1988) discusses another way to separate risk aversion and intertemporal substitutability, using an unconventional utility function.

In this model, neither consumption nor market prices follow a geometric random walk with constant parameters. Stapleton and Subrahmanyam (1988) show that if one of these fails to follow a geometric random walk (and utility shows constant elasticity) the other must fail as well.

Kandel and Stambaugh (1988) give similar results in an exchange model with both mean reversion and consumption smoothing. Their model has two state variables 
other than wealth. They say that the price of risk can fail to measure relative risk aversion when the consumption growth rate shows serial correlation. This is similar to my notion that 1 and relative risk aversion can differ.

\section{AN EQUILIBRIUM MODEL}

We will assume identical individuals who live forever. All variables will be per capita. Let's write $w$ for wealth, $c$ for the consumption rate, and $x$ for the level of investment in units of risk.

As investors, individuals can choose from a continuous range of technologies for investing their real assets. The technology corresponding to risk level $x$ has an expected return equal to interest at rate $r$ plus $x$ times the price of risk $a$. Thus the equation governing changes in wealth is:

$$
d w=(r w-c+a x) d t+x d z
$$

Describing the technology in this way allows the risk of the market to reach any: level we choose. In more conventional models, like Merton's (1971), there are two technologies: riskless and risky. The risk of the market is limited to the level reached when everything is invested in the risky technology. So long as the amount invested in the risky asset stays below $100 \%$, this conventional technology will give exactly the same results as the one $I$ use.

We will assume that changes in the price of risk are perfectly correlated with market returns. We have two state variables (the level of wealth and the current price of risk) but only one stochastic variable $z$. We assume the price of risk follows a simple process of the form given by equation (2). In a more general model, we would use separate and imperfectly correlated stochastic variables for wealth and the price of risk. None of our qualitative results depend on our assumption that changes in the price of risk are perfectly correlated with market returns.

$$
d a=f(a) d t+g(a) d z
$$

Since we want $a$ to be positive or occasionally zero, we will choose $f(a)$ and $g(a)$ to satisfy:

$$
f(0)>0
$$




$$
g(0)=0
$$

Let's write $v(c)$ for the direct utility function, $\rho$ for the utility discount rate, and $u(w, a)$ for the indirect utility function. We will assume that $\rho$ is large enough to give a finite value for the indirect utility function. Since no variables depend directly on time, the basic maximization equation is:

$$
u(w, a)=\max _{c, x}[E[u+d u] /(1+\rho d t)+v(c) d t]
$$

Expanding $d u$, substituting from equations (1) and (2), and using subscripts to refer to derivatives, we have:

$$
\begin{aligned}
u= & \max _{c, x}\left[u+\left[(r w-c+a x) u_{1}+f u_{2}\right.\right. \\
& \left.\left.+\frac{1}{2} x^{2} u_{11}+x g u_{12}+\frac{1}{2} g^{2} u_{22}-\rho u+v(c)\right] d t\right]
\end{aligned}
$$

The first order conditions are (7) and (8).

$$
\begin{aligned}
& 0=-u_{1}+v_{1}(c) \\
& 0=a u_{1}+x u_{11}+g u_{12}
\end{aligned}
$$

Assuming that $c(w, a)$ and $x(w, a)$ satisfy (7) and (8), equation (6) becomes (9).

$$
0=(r w-c+a x) u_{1}+f u_{2}+\frac{1}{2} x^{2} u_{11}+x g u_{12}+\frac{1}{2} g^{2} u_{22}-\rho u+v(c)
$$

In equations (7)-(9), we are taking $c$ and $x$ to be $c(w, a)$ and $x(w, a)$.

Let's write $\delta$ for the elasticity of marginal utility with respect to consumption. (We are purposely not calling it relative risk aversion.) Thus the direct utility: function satisfies: 


$$
-\frac{c v_{11}(c)}{v_{1}(c)}=\delta
$$

Assuming that marginal utility decreases as consumption increases, $\delta$ will be positive. We will assume throughout this paper that $\delta$ is constant.

The local volatility of consumption comes from changes in either of the state variables $w$ and $a$. Recall, however, that we are assuming that changes in $w$ and $a$ are perfectly correlated. Writing $\sigma_{c}^{2}$ for the variance rate of the percentage change in consumption, we have:

$$
\sigma_{c}=\frac{\left(x c_{1}+g c_{2}\right)}{c}
$$

Taking derivatives with respect to $w$ and $a$ of (7), we have equations (12) and (13).

$$
\begin{aligned}
& u_{11}=v_{11} c_{1} \\
& u_{12}=v_{11} c_{2}
\end{aligned}
$$

Substituting from (12) and (13) into (8), we have:

$$
0=a+\left(x c_{1}+g c_{2}\right) \frac{v_{11}}{v_{1}}
$$

Using equations (10) and (11) together with (14), we have:

$$
\sigma_{c}=\frac{a}{\delta}
$$

Note that equation (15) holds at all times, even though the price of risk $a$ is changing. Also note that equation (15) follows only from first order conditions ( 7 ) and (8). We did not use equation (9). Finally, note that equation (15) does not contain either $f$ or $g$. 
Next, let's derive an expression for the volatility $\sigma_{w}$ of wealth. Again, the square of the volatility will be a variance rate, so the volatility will have the dimension "inverse square root of time."

Since $x$ is the investment in the risky asset in units of risk (or volatility), we have:

$$
\sigma_{w}=\frac{x}{w}
$$

Let's look for a solution in which consumption and investment are both proportional to wealth, and in which the indirect utility function shows constant elasticity of marginal utility. In fact, let's use the same function $h(a)$ in the expressions for consumption and indirect utility to satisfy equation (7):

$$
\begin{aligned}
& c=w / h(a) \\
& x=y(a) w \\
& u=h(a)^{\delta} w^{(1-\delta)} /(1-\delta) \\
& v=c^{(1-\delta)} /(1-\delta)
\end{aligned}
$$

Substituting from equations (18) and (19) into equation (8), we have:

$$
y=a / \delta+g h_{1} / h
$$

Using equations (15) and (16), this becomes:

$$
\sigma_{w}=\sigma_{c}+g h_{1} / h
$$

Equation (17) implies that:

$$
c_{2} / c=h_{1} / h
$$

Combining equations (22) and (23), we have: 


$$
\sigma_{w}=\sigma_{c}-g c_{2} / c
$$

To model mean reversion in the market, we make g negative in equation (2). When $c_{2}$ is positive, this means:

$$
\sigma_{w}>\sigma_{c}
$$

In Merton's $(1969,1971)$ models, $g$ is zero, and $\sigma_{w}$ is equal to $\sigma_{c}$. As $g$ becomes more negative, $c_{2} / c$ becomes more positive, and the difference between $\sigma_{w}$ and $\sigma_{c}$ increases rapidly (since it is the product of two increasing numbers). By making $g$ sufficiently negative, we can make $\sigma_{w}$ large relative to $\sigma_{c}$.

So far, all our results depend on first order conditions ( 7 ) and (8), but none depend on equation (9). Let's substitute from equations (17) - (21) in equation (9). This gives a differential equation (26) for $h(a)$.

$$
\begin{aligned}
0= & \delta /(1-\delta)+\left[r-\rho /(1-\delta)+\frac{1}{2} a^{2} / \delta\right] h \\
& +[\delta f /(1-\delta)+a g] h_{1}+\frac{1}{2} \delta g^{2} h_{11} /(1-\delta)
\end{aligned}
$$

Note that this is a linear, second order, ordinary differential equation. Given choices for $f(a)$ and $g(a)$, we can solve it analytically or numerically.

Here are some possible choices for $f(a)$ and $g(a)$, where $n, b$, and $m$ are positive constants.

$$
\begin{gathered}
f(a)=n(b-a) \\
g(a)=-m a
\end{gathered}
$$

With these choices (and with many other choices) the price of risk a will remain above zero and will fall back when it goes too high. It will have a mean level, and so will $f(a), g(a), h(a), \sigma_{c}$ and $\sigma_{w}$. The constant $b$ will be one measure of $a$ 's central tendency. 
Let us define $k$ as the ratio of the mean levels of $\sigma_{w}$ and $\sigma_{\mathfrak{c}}$ :

$$
\bar{\sigma}_{w}=k \bar{\sigma}_{\mathrm{c}}
$$

In the light of equations (15), (16), (18), and (29) it seems natural to define risk aversion $\gamma$ as:

$$
\gamma=\delta / k
$$

Equation (30) is the natural definition for risk aversion because it makes the equilibrium amount of risk that the investor chooses depend on the price of risk and on risk aversion in a simple way. Moreover, in the limiting case where the price of risk is constant, we have:

$$
\gamma=\delta
$$

Another way to interpret this definition of risk aversion is as follows. The elasticity $\delta$ can be estimated from the average price of risk and the average consumption volatility through equation (15). But consumption volatility depends on the differencing interval: it is larger for longer intervals. In the limit as the interval becomes long, the elasticity estimated through equation (13) approaches $\gamma$ as defined in equation (30). Naik and Ronn (1988) also emphasize the importance of the differencing interval in estimating relative risk aversion. Constantinides (1988) distinguishes elasticity and risk aversion in much the same way I do.

Here is another way to think about the difference betwen the elasticity of utility and relative risk aversion. Look at the derived utility function in (17). If we vary $w$ holding $a$ fixed, we have utility changes associated with the elasticity. But if we allow $a$ to change along with $w$, since they are correlated, we have utility changes associated with relative risk aversion.

The literature on the "equity premium" has implicitly assumed that (31) always holds. That's one reason why the estimates of risk aversion have seemed high. By separating elasticity and risk aversion, we are able to explain smooth consumption without resorting to high risk aversion.

Using a model of this form, we can match features of the world as follows.

1. Real interest rate. We set the model's constant real interest rate to match our estimate of the average real rate. In a more general model, we can allow the real rate to vary. We can even give it its own stochastic variable. 
2. Market risk premium. The market risk premium does not appear explicitly in the model. We use the average of the price of risk $a$ in the model to match the observed ratio of market risk premium to market volatility.

3. Consumption volatility. Using equation (15), we choose elasticity $\delta$ together with our estimate of the average price of risk to match the average volatility of consumption. In a more general model, we can let the elasticity be a state variable with its own stochastic variable, so utility will become state dependent while remaining additive and separable.

4. Wealth volatility. Using our estimate of the average volatility of consumption. we choose $g(a)$ to match the average volatility of wealth. In a more general model, we can add a stochastic variable that will allow us to make changes in consumption volatility and changes in wealth volatility less than perfectly correlated.

5. Mean reversion. We can choose $f(a)$ to give the amount of mean reversion we want, in the sense of the rate at which the price of risk returns toward its average value after a deviation. In a more general model, we can put in more dimensions to mean reversion.

6. Consumption growth rate. We can choose the utility discount rate $\rho$ to give the consumption rate and thus the consumption growth rate we want. A higher utility discount rate means a higher consumption rate and thus a lower consumption growth rate. We can define two consumption growth rates: a true growth rate that depends on the interest rate, the consumption rate, and the market risk premium as in equation (1); and a certainty equivalent growt h rate that depends only on the interest rate and the consumption rate.

I resist trying to find the actual values of the factors in the model that let us match various features of the world. I don't know what I would make of the values. If the values let us match features of the world, then they must, in this sense, be "reasonable." If there are features of the world other than numbers 1-6 above that we want to match (such as interest rate volatility) then I will want to add factors to the model that correspond to these features.

While it is nice to have a model with fewer factors than features of the world we are trying to match, I don't consider it crucial. Any model is only an approximation. As we make the model more precise, we will always add factors so we can match more features of the world. 
While we used a model that starts with technology and derives equilibrium consumption and investment, we could have derived the same solution in an exchange economy like that of Lucas (1978). We start with a consumption process depending on two state variables that we call $w$ and $a$, and derive the interest rate and the distribution of risky asset returns. If we start with the consumption process $c(w, a)$ we will find that the equilibrium interest rate is constant at $r$, that $w$ is always equal to wealth, and that $a$ is always equal to the price of risk. Production and exchange models of this kind are interchangeable.

In fact, Abel (1988) has an exchange model that is quite similar to my production model. He has an endowment of consumption goods each period, where the mean and coefficient of variation both fluctuate through time.

In Abel's model, stock prices fall when endowments become riskier, other things equal. In my model, investments becomes riskier when stock prices fall and the price of risk rises. Both models are consistent with an inverse relation between stock prices and risk. 


\section{REFERENCES}

Abel, Andrew B. "Stock Prices Under Time-Varying Dividend Risk: An Exact Solution in an Infinite-Horizon General Equilibrium Model." Journal of Monetary Economics 22 (November, 1983), 375-393.

Black, Fischer. "An Equilibrium Model of the Crash." in Stanley Fischer, (ed.), NBER Macroeconomics Annual 1988. (Massachusetts: MIT Press), 269-275.

Blanchard, Olivier Jean and N. Gregory Mankiw. "Consumption: Beyond Certainty Equivalence." Harvard Institute of Economic Research, Discussion Paper No. 13iS (April, 1988).

Brock, William A. "Asset Prices in a Production Economy." in John J. McCall, ed.. The Economics of Information and Uncertainty, University of Chicago Press, 1982.

Campbell, John Y. and N. Gregory Mankiw. "Consumption, Income, and Interest Rates: The Euler Equation Approach Ten Years Later." Prepared for the NBER Macroeconomics Conference, (February, 1989).

Cecchetti, Stephen G., Pok-sang Lam, and Nelson C. Mark. "Mean Reversion in Equilibrium Asset Prices." NBER Working Paper No. 2762, (November, 1988).

Cochrane, John H. "How Big is the Random Walk in GNP?" Journal of Political Economy 96 (October, 1988), 893-920.

Constantinides, George M. "Habit Formation: A Resolution of the Equity Premium Puzzle." University of Chicago, Graduate School of Business, Working Paper No. 225 (February, 1988).

Epstein, Larry G. "Risk Aversion and Asset Prices." Journal of Monetary Economics 22 (September, 1988), 179-192.

Fama, Eugene F. and Kenneth R. French. "Permanent and Temporary Components of Stock Prices." Journal of Political Economy 96 (April, 1988), 246-273.

Friend, Irwin and Marshall Blume. "The Demand for Risky Assets." American Economic Review 65 (December, 1975), 900-922.

Hall, Robert E. "Intertemporal Substitution in Consumption." Journal of Political Economy 96 (April, 1988), 339-357. 
Hall, Robert E. "Stochastic Implications of the Life Cycle - Permanent Income Hypothesis: Theory and Evidence." Journal of Political Economy 86 (December, 1978), 971-987.

Hansen, Lars P. and Kenneth J. Singleton. "Stochastic Consumption, Risk Aversion and the Temporal Behavior of Asset Returns." Journal of Political Economy 91 (April, 1983), 249-266.

Kandel, Shmuel and Robert F. Stambaugh. "Modeling Expected Stock Returns for Long and Short Horizons." Wharton School Working Paper, University of Pennsylvania (December, 1988).

Kim, Myung Jig, Charles R. Nelson and Richard Startz. "Mean Reversion in Stock Prices? A Reappraisal of the Empirical Evidence." NBER Working Paper No. 2795 (December, 1988).

Lucas, Robert E., Jr. "Asset Prices in an Exchange Economy." Econometrica 46 (November, 1978), 1429-1445.

Mehra, Rajnish and Edward C. Prescott. "The Equity Premium: A Puzzle." Journal of Monetary Economics 15 (March, 1985), 145-161.

Merton, Robert C. "On Estimating the Expected Return on the Market." Journal of Financial Economics 8 (December, 1980), 323-361.

Merton, Robert C. "An Intertemporal Capital Asset Pricing Model." Econometrica 41 (September, 1973), 867-887.

Merton, Robert C. "Optimum Consumption and Portfolio Rules in a Continuous-Time Model.” Journal of Economic Theory 3 (December, 1971), 373-413.

Merton, Robert C. "Lifetime Portfolio Selection Under Uncertainty: The Continuous Time Case." Review of Economics and Statistics 51 (August, 1969), 247-257.

Naik, Vasanttilak T. and Ehud I. Ronn. "The Impact of Time Aggregation and Sampling Interval on the Estimation of Relative Risk Aversion and the Ex Ante Real Interest Rate." University of Chicago Working Paper No. 240, (August, 1988).

Poterba, James M. and Lawrence H. Summers. "Mean Reversion in Stock Prices: Evidence and Implications." Journal of Financial Economics 22 (October, 1988). 
Prescott, Edward C. "Theory Ahead of Business Cycle Measurement." Federal Reserve Bank of Minneapolis Quarterly Review (Fall, 1986), 9-22.

Stapleton, Richard C. and Marti G. Subrahmanyam. "Risk Aversion and The Intertemporal Behavior of Asset Prices." Churchill College, University of Cambridge Working Paper 88-39 (April, 1988).

Summers, Lawrence H. "Does the Stock Market Rationally Reflect Fundamental Values?" Journal of Finance 41 (July, 1986), 591-601.

Sundaresan, Suresh M. "Intertemporally Dependent Preferences in the Theories of Consumption, Portfolio Choice and Equilibrium Asset Pricing." Graduate School of Business Working Paper, Columbia University (January, 1987).

Zeldes, Stephen P. "Consumption and Liquidity Constraints: An Empirical Investigation." Journal of Political Economy 97 (April, 1989), 305-346. 
</ref_section> 